\title{
Distribution of freshwater caridean shrimps and prawns (Atyidae and Palaemonidae) from Southern Kyushu and adjacent islands, Kagoshima Prefecture, Japan
}

\section{Hiroshi Suzuki, Noboru Tanigawa, Takayuki Nagatomo and Eiji Tsuda}

Abstract. - Seventeen species of freshwater caridean shrimps and prawns (Atyidae and Palaemonidae) are recorded from mainland Kagoshima, Uji Gunto, Ohsumi Shoto and Tokara Retto, Southern Japan. Distribution of three Macrobrachium prawns: M. equidens, M. latimanus and $M$. gracilirostre, are newly recorded in the surveyed areas by the present study. Though the fauna of the surveyed areas has many tropical and subtropical species, it is characterized as a complex mixture of southern and northern species. In the Sendai, Manose and Kimotsuki Rivers, the longitudinal distribution of shrimps was also surveyed. The distribution is affected by a dam or a natural vertical wall as mentioned in previous papers. The amphidromous species, Caridina leucosticta, C. serratirostris, C. typus, $M$. formosense, and $M$. japonicum, inhabited slow flowing reaches near the river mouth, while the landlocked Neocaridina denticulata and Palaemon (Palaemon) paucidens were distributed upstream from the dam or the steep reaches.

\section{Introduction}

In the region between Okinawa and the main island of Kyushu, many small islands are sporadically located forming an arcuate archipelago called the Ryukyu Islands. This region has attracted the attention of biogeographers for a long time, and two biogeographical lines, the Miyake and Watase lines, have been drawn in the northern area of the archipelago (Tokuda, 1969). This region also has an interesting oceanographical character; the warm Kuroshio Current from the tropics flows northward to the Kyushu mainland along the Ryukyu Islands and divides into two substreams in the northeast part of the archipelago (Ekman, 1953; Kawai, 1991). Thus, the northern area of the Ryukyu Islands and the southernmost part of Kyushu mainland, which together form Kagoshima Prefecture, are thought to be interesting areas for biogeographical studies.

Many scientists have done researches on the islands in the area. Kamita (1963, 1970) reported that the faunas of freshwater shrimps on Tanega-shima, Yaku-shima and Amami Ohshima are similar to those of Middle and Southern Honshu. Shokita (1975, 1979) studied the fauna, distributions, and life histories of freshwater shrimps in the Ryukyu Islands, and discussed their speciation and the formative process of the fauna. The faunas in the islands of Tokara Retto and mainland Kagoshima are, however, not yet accurately surveyed. Knowledge of the fauna in these areas should provide important information on the biogeography of freshwater shrimps.

\section{Material and Methods}

Surveys were conducted at Uji-jima on May 14, 1986; at Shimokoshiki-jima on 
June 4, 1987; and occasionally on mainland Kagoshima, Ohsumi Shoto and Tokara Retto from 1990 to 1991. Samples were taken from inland waters such as rivers, ponds, and springs. In the Sendai, Manose, and Kimotsuki Rivers, surveys on longitudinal distribution were also conducted. These sample sites are indicated by solid circles in Fig. 1.

Shrimps were mainly collected by a nylon scoop net $\left(\right.$ mesh $\left.1 \mathrm{~cm}^{2}\right)$ with a mouth size of $100 \times 65 \mathrm{~cm}$. Additional samples were taken by a nylon landing net (mesh 0.025 $\mathrm{cm}^{2}$ ) with a mouth size of $30 \times 20 \mathrm{~cm}$. Because atyid shrimps and palaemonid prawns were found in aquatic grass beds, under stones, between crevices, and among fallen leaves, a sweeping method was applied for quantitative sampling. A total of ten net sweeps were made at each site.

Sampling was not done at Suwanose-jima and Kodakara-jima of Tokara Retto since there are no natural rivers, lakes or ponds on these islands. On Akuseki-jima, the only small river has been modified to serve as the domestic water supply so likewise, specimens could not be collected.

\section{Results}

In the surveyed areas, a total of seventeen species of freshwater caridean shrimps and prawns were collected, belonging to four genera of Atyidae and two genera of Palaemonidae.

The collected shrimps and prawns are listed below. The Arabic numerals shown in parentheses indicate the total number of collected shrimps, preceded by another Arabic numeral indicating sampling sites.

\section{Family Atyidae}

Atyopsis spinipes (Newport, 1847)

Ohsumi Peninsula: 164 (1).

Yaku-shima: 211 (2).

Kuchino-shima: 216 (1).

Nakano-shima: 217 (18); 218 (1).

\section{Paratya compressa compressa}

(De Haan, 1844)

Ohsumi Peninsula: 152 (12); 153 (4); 155 (5); 157 (17); 159 (3); 160 (60); 163 (20); 164 (7); 165 (1).

Yaku-shima: 212 (1).

Takara-jima: 226 (6).

Caridina typus $\mathrm{H}$. Milne Edwards, 1837

Satsuma Peninsula: 38 (17); 60 (1); 63

(8); 67 (4); 76 (10); 77 (9); 84 (1); 85

(2); 89 (11); 91 (5); 92 (1); 95 (15).

Ohsumi Peninsula: 136 (7); 137 (2); 144 (5); 151 (1); 152 (3); 154 (6); 155 (3); 157 (12); $160(3) ; 163(1) ; 164(1) ; 171$ (1); 181 (1); 182 (1).

Shimokoshiki-jima: 188 (6).

Tanega-shima: 192 (3).

Kuchinoerabu-jima: 196 (6).

Yaku-shima: 198 (21); 199 (1); 200 (1); 202 (26); 203 (33); 205 (1); 206 (61); 208 (4); 209 (2); 210 (13); 212 (20); 213 (2).

Nakano-shima: $217 \quad$ (22); $219 \quad$ (3); 220 (7); 222 (13); 223 (2).

Takara-jima: 225 (18); 226 (32).

Caridina longirostris H. Milne Edwards, 1837

Satsuma Peninsula: 34 (1).

Tanega-shima: 192 (2); 193 (1).

Yaku-shima: 205 (1).

Caridina leucosticta Stimpson, 1860

Satsuma Peninsula: 8 (10); 13 (4); 14 (2); 20 (10); 32 (3); 33 (16); 34 (2); 35 (2); 36 (82); 38 (1); 39 (9); 43 (45); 44 (3); 45 (29); 47 (25); 48 (10); 51 (11); 53 (48); 58 (130); 59 (55); 60 (20); 64 (1); 67 (17); 74 (22); 77 (29); 85 (4); 89 (33); $95 \quad$ (5); $101 \quad$ (6); $105 \quad$ (15); 110 (119); 113 (13).

Ohsumi Peninsula: 115 (20); 120 (56); 122 (9); 125 (5); 129 (36); 132 (2); 134 (30); $135 \quad$ (6); $137 \quad$ (12); 139 (2); 141 (21); 151 (15); 157 (15); 159 (7); 164 (287); 166 (1); 167 (112); 168 (130); 169 (51); 171 (38); 172 (46); 173 (1); 175 (11); 176 (18); 178 (2); 181 (11). 


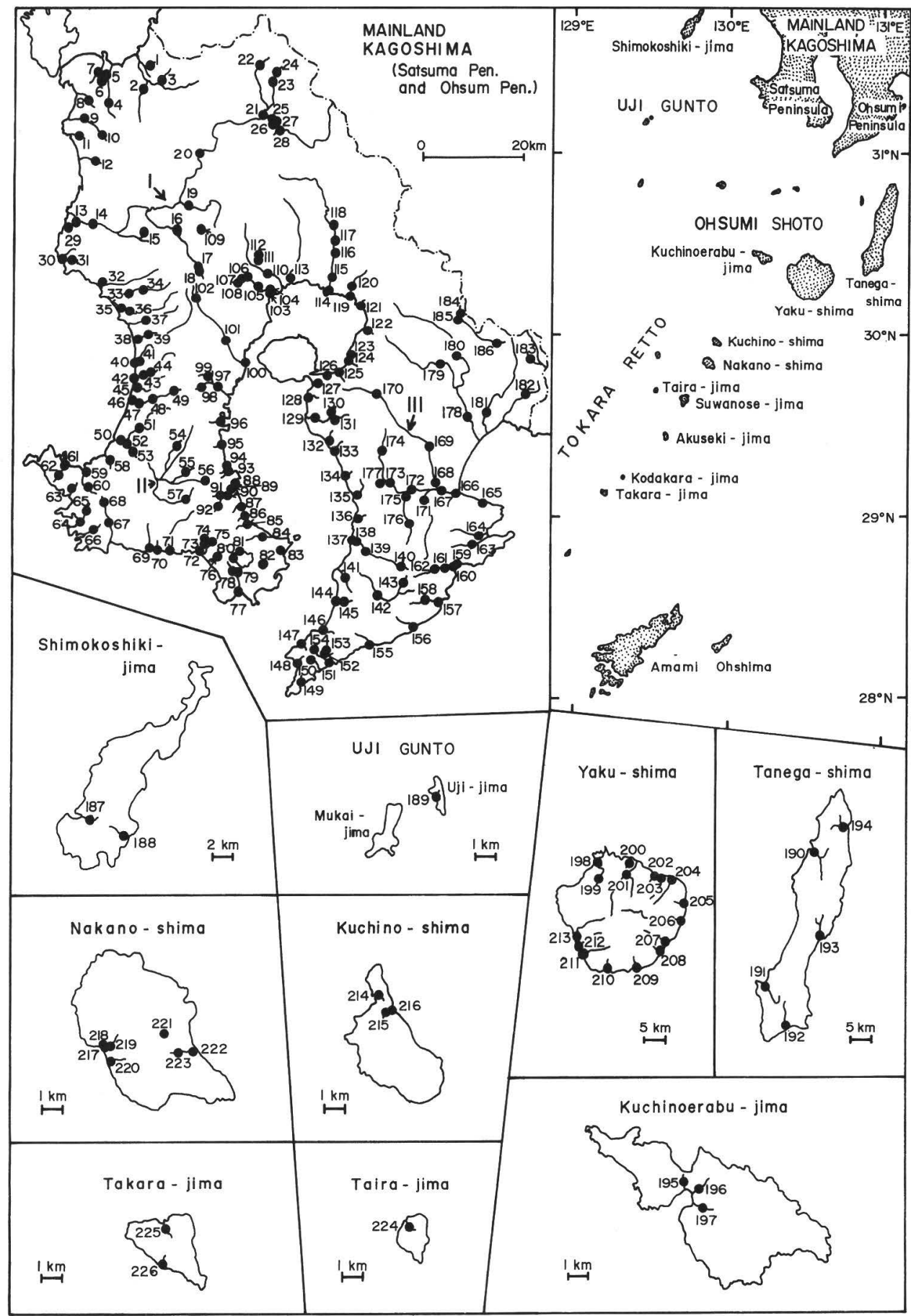

Fig. 1. Map showing the sample sites (solid circles) in mainland Kagoshima, Shimokoshiki-jima, Uji-jima, Ohsumi Shoto, and Tokara Retto. Arabic numerals show the site number. I; the Sendai river, II; the Manose river, and III; the Kimotsuki river. Note: "gunto", "shoto", and "retto" mean an insular group. "shima" and "jima" mean island. 
Tanega-shima: 192 (12); 193 (5).

Yaku-shima: 203 (13); 204 (2).

Caridina serratirostris De Man, 1892

Ohsumi Peninsula: 137 (1); 151 (2); 157 (1); 164 (4); 168 (1).

Shimokoshiki-jima: 188 (3).

Yaku-shima: 203 (6); 204 (1); 205 (3).

Caridina japonica De Man, 1892

Satsuma Peninsula: 12 (2); 65 (4).

Ohsumi Peninsula: 136 (1); 140 (6); 144 (12); 145 (12); $146 \quad$ (4); 150 (2); 152 (22); 154 (4); 156 (17); 157 (1); 158 (13); 162 (7); 164 (7); 183 (9).

Shimokoshiki-jima: 188 (30).

Uji-jima: 189 (2).

Kuchinoerabu-jima: 197 (1).

Yaku-shima: 199 (3); 200 (8); 202 (1); 205 (8); 207 (16); 209 (4); 213 (1).

Nakano-shima: 222 (2).

Takara-jima: 226 (20).

Neocaridina denticulata (De Haan, 1849)

Satsuma Peninsula: 20 (27); 54 (10); 55 (3); 76 (3); 82 (4); 97 (52); 98 (225); 99 (8).

Ohsumi Peninsula: $116(39) ; 117(5) ; 118$ (40); 172 (2); 173 (4); 177 (57).

\section{Family Palaemonidae}

\section{Palaemon (Palaemon) paucidens}

De Haan, 1844

Satsuma Peninsula: 22 (57); 67 (1); 76 (14); 79 (15); 80 (7); 81 (5); 83 (13).

Ohsumi Peninsula: 155 (67); 157 (126); 159 (23); 160 (2); 164 (1); 170 (34); 178 (2); 182 (1).

$\begin{array}{lll}\text { Tanega-shima: } 191 \quad \text { (27); } 192 \quad \text { (1); } 194 & \end{array}$ (10).

Yaku-shima: 198 (46); 201 (11); 202 (5); 203 (14); 204 (13); 205 (22); 213 (1).

Macrobrachium lar (Fabricius, 1798)

Satsuma Peninsula: 76 (2).

Ohsumi Peninsula: 146 (4).

Kuchinoerabu-jima: 195 (7); 197 (3).

Yaku-shima: 202 (5); 203 (3); 205 (2); 206 (42); 207 (4); 208 (10); 209 (9);
210 (2); 211 (38); 212 (13); 213 (7).

Kuchino-shima: 214 (3); 216 (5).

Nakano-shima: 217 (4); 219 (3).

Macrobrachium australe (Guérin

Méneville, 1838)

Satsuma Peninsula: 45 (1).

Tanega-shima: 193 (5).

Nakano-shima: 217 (1); 219 (3).

Macrobrachium nipponense (De Haan,

1849)

Satsuma Peninsula: 13 (1); 14 (1); 45 (1).

Macrobrachium japonicum (De Haan,

Satsuma Peninsula: 12 (1); 33 (5); 34 (1); 64 (2).

Ohsumi Peninsula: 129 (7); 136 (12); 139 (9); 146 (11); 148 (2); 154 (10); 155 (3); 156 (4); 160 (1); 161 (2); 163 (2); 164 (4); 165 (7); 176 (4); 178 (24); 182 (9).

Shimokoshiki-jima: 187 (10); 188 (5).

Kuchinoerabu-jima: 195 (3).

Yaku-shima: 200 (1).

Nakano-shima: 222 (2).

Macrobrachium equidens (Dana, 1852)

Tanega-shima: 190 (1); 193 (12).

Macrobrachium latimanus (Von Martens,

Ohsumi Peninsula: 146 (6). 1868)

Kuchinoerabu-jima: 197 (4).

Yaku-shima: 200 (1); 208 (9).

Macrobrachium formosense Bate, 1868

Satsuma Peninsula: 8 (3); 12 (14); 13 (8); $14(3) ; 16(4) ; 19(1) ; 30(5) ; 32(2) ; 33$ (4); 34 (9); 35 (34); 36 (14); 37 (16); $38(16) ; 39(3) ; 40(1) ; 43(16) ; 45(38)$; $46(7) ; 47(3) ; 48(5) ; 49(3) ; 50(5) ; 51$ (109); 53 (5); 58 (17); 59 (56); 60 (10); 61 (1); 62 (11); 63 (5); 64 (9); 65 (5); 66 (2); 67 (34); 68 (5); 69 (11); 71 (1); 72 (1); 73 (4); 77 (5); 86 (21); 89 (4); 90 (5); 95 (11); 110 (3).

Ohsumi Peninsula: 125 (7); 128 (4); 129 (17); $131 \quad$ (4); 132 (3); 133 (30); 134 (28); $136 \quad$ (1); $137 \quad$ (3); $138 \quad$ (1); 139 
Table 1. A summary of the distribution of freshwater shrimps and prawns in mainland Kagoshima, Shimokoshiki-jima, Uji-jima, Ohsumi Shoto, and Tokara Retto. No shrimp was collected at Taira-jima.

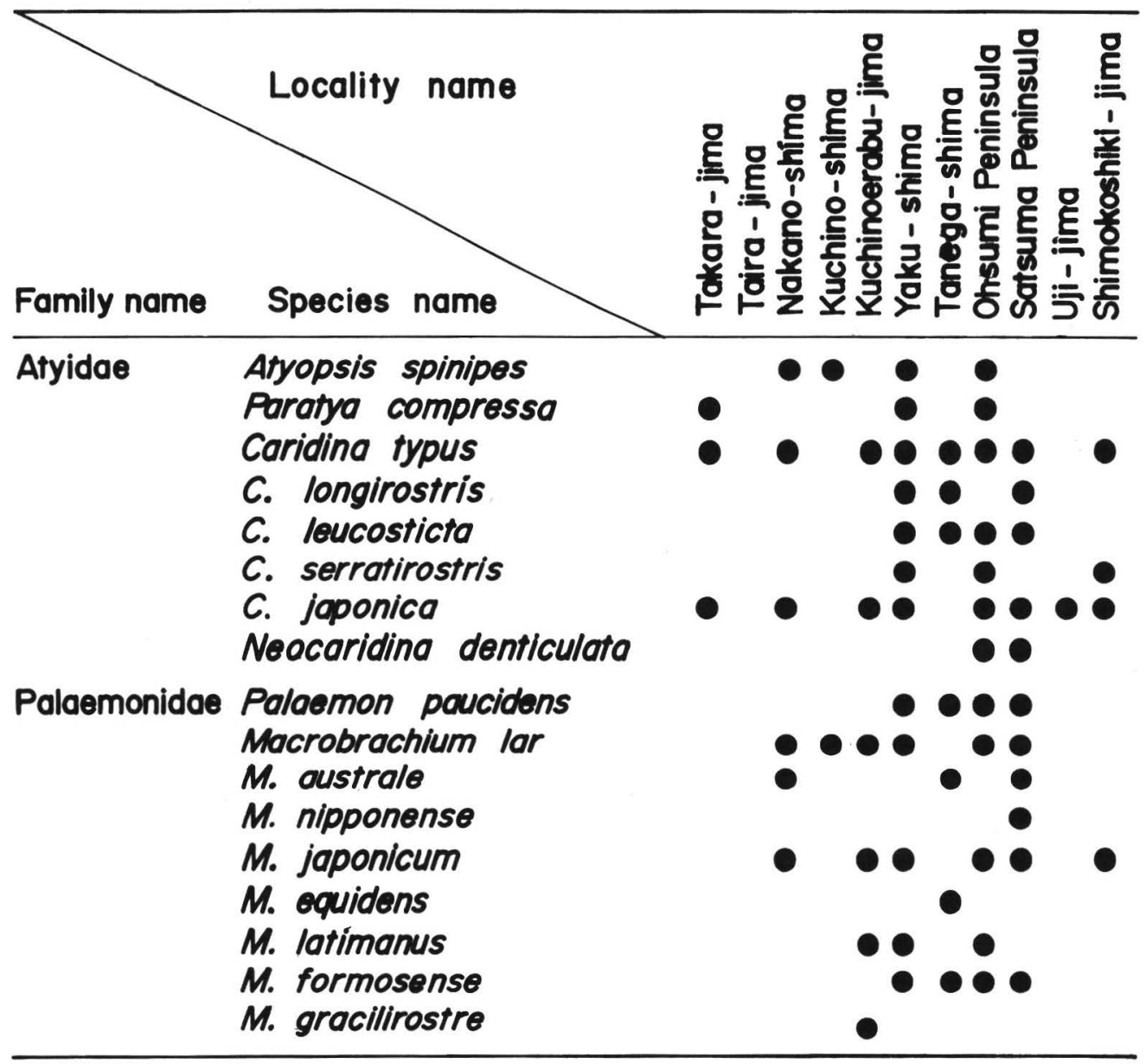

(10); 141 (9); 147 (10); 149 (52); 151 (20); 155 (6); 157 (12); 159 (7); 160 (5); $163 \quad(16) ; 164 \quad(53) ; 166 \quad(1) ; 167$ (269); 168 (116); 169 (44); 171 (11); 172 (120); $173(36) ; 174(2) ; 175(18)$; 176 (67); 178 (2); 181 (9); 182 (9).

Tanega-shima: 191 (1); 192 (4); 193 (12); 194 (3).

Yaku-shima: 203 (1); 204 (3).

Macrobrachium gracilirostre (Miers, 1875)

Kuchinoerabu-jima: 197 (2).

Nine out of seventeen species were abundant (n >> 23); P. compressa, C. typus, C. leucosticta, C. japonica, N. denticulata,
$P$. paucidens, $M$. lar, M. japonicum, and $M$. formosense. On the basis of their geographical distribution these nine species could be divided into four groups as follows (Table 1); 1) species distributed from mainland Kagoshima (Satsuma and Ohsumi Peninsula) to the Tokara Retto, that is C.typus, C. japonica, M. lar, and M. japonicum, 2) species distributed from mainland Kagoshima to the Ohsumi Shoto, that is $C$. leucosticta, P. paucidens, and M. formosense, 3) species distributed from the Ohsumi Peninsula to the Tokara Retto, that is $P$. compressa, and 4) species distributed only on mainland Kagoshima, that is $N$. 


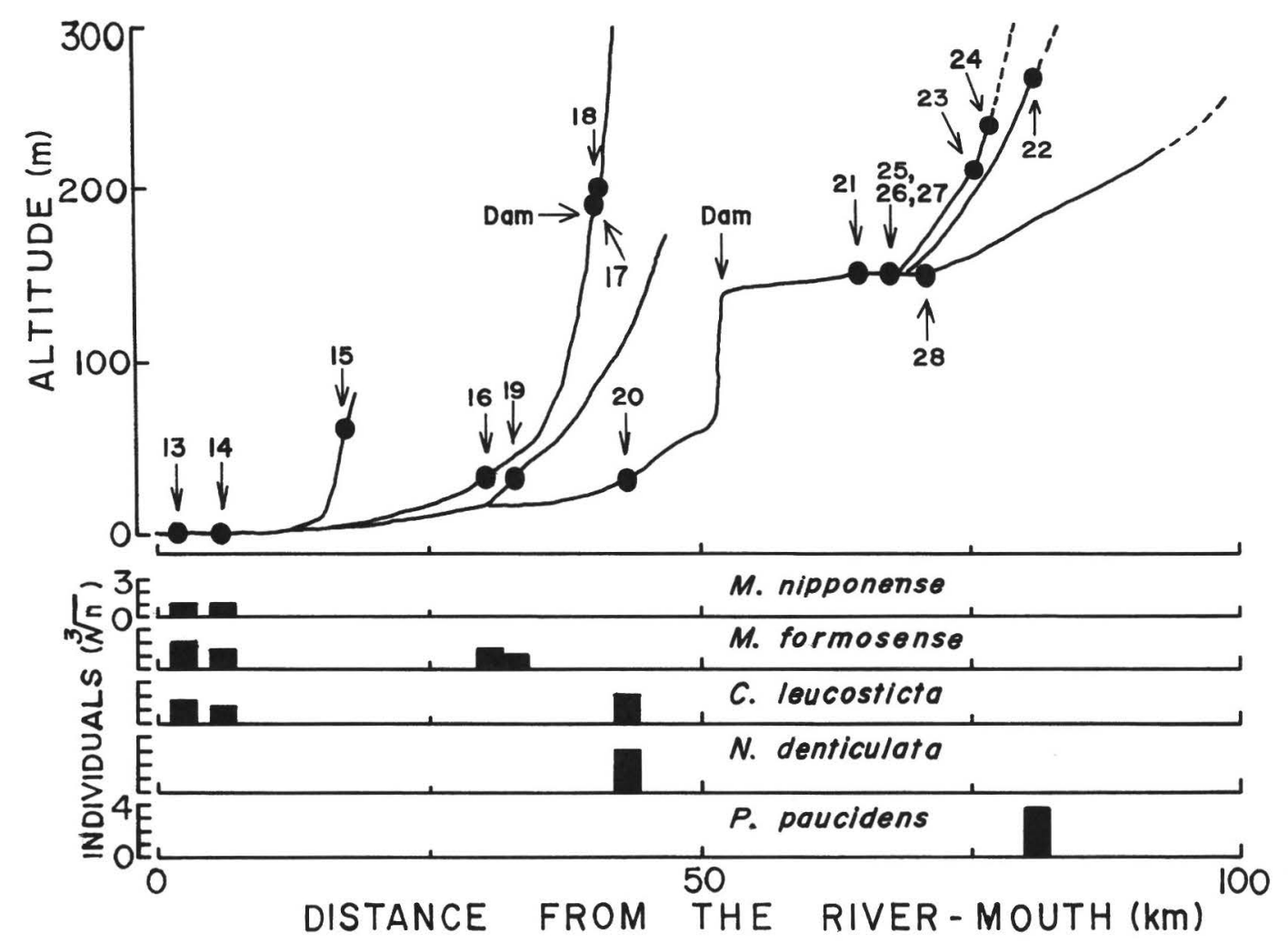

Fig. 2. Longitudinal distribution and abundance of inland water shrimps and prawns in the Sendai River. Arabic numerals show the site number.

\section{denticulata.}

The other eight species were less abundant (n < 23); A. spinipes, C. longirostris, $C$. serratirostris, $M$. australe, $M$. nipponense, M. equidens, M. latimanus, and M. gracilirostre. Most of them may be rare in the surveyed area, while $M$. nipponense may be under represented because of the sampling technique used.

Longitudinal distributions in the Sendai, Manose and Kimotsuki Rivers: Caridina leucosticta and $M$. formosense showed wide longitudinal distributions upstream from the river mouth in the three surveyed rivers (Figs. 2-4). Landlocked N. denticulata were found in the middle or upper reaches. No shrimps or only landlocked $P$. paucidens are found at the sites in the steep reaches (sites 15 in Fig. 2 and 56 in Fig. 3) and upstream from a dam (sites 17-18, 21-
28 in Fig. 2 and 170 in Fig. 4).

\section{Discussion}

Geographical distribution: The number of species of shrimps varied in the surveyed islands and peninsula (Table 1). The number of species of birds or butterflies is known to be affected by island size (= the area of an island); large islands have many species of animals (MacArthur \& Wilson, 1967; Kimoto, 1979). In the case of freshwater shrimps, the whole area of inland water must be used as the index of island size for our analysis. However an accurate estimate of the area of inland water is not yet available for each island, but the area of inland water should be related to the area of an island. Therefore the area of an island or a peninsula may be used as the index of 


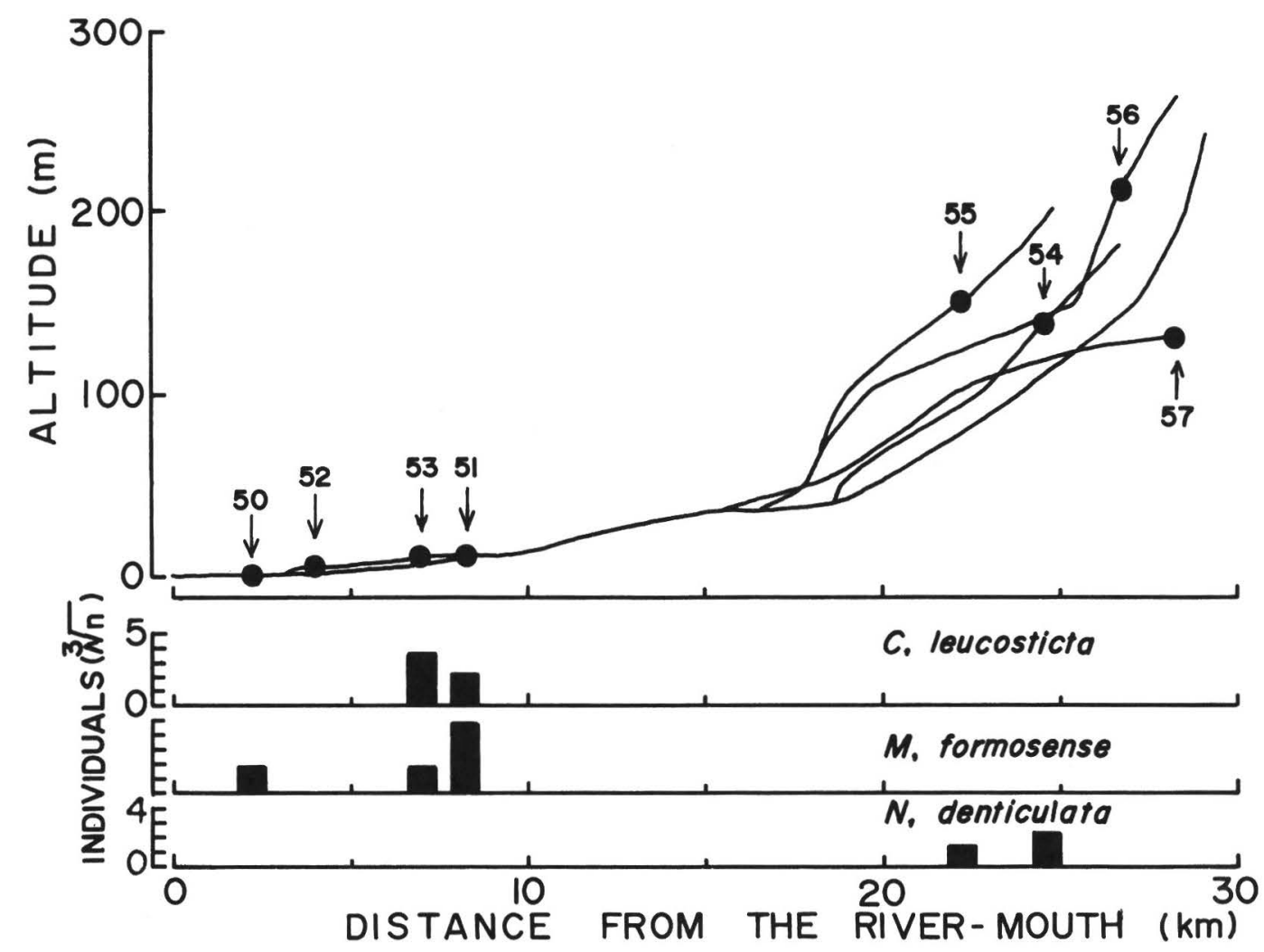

Fig. 3. Longitudinal distribution and abundance of inland water shrimps and prawns in the Manose River. Arabic numerals show the site number.

island size in the case of these freshwater shrimps. The number of species of shrimp showed a positive correlation with area, having a high coefficient of correlation $(\mathrm{r}=$ 0.92) (Fig. 5). Thus, in the case of freshwater shrimps, the number of species inhabiting an island is thought to be affected by island size in the same way as for birds and butterflies.

The shrimps obtained in this survey were mainly tropical and subtropical species. The occurrences of temperate or continental species, such as $N$. denticulata, $P$. paucidens and $M$. nipponense, suggest that the fauna is a complex mixture of southern and northern species as mentioned by Shokita (1975, 1979). The present study made it clear that $N$. denticulata was distributed northward from the Miyake line, drawn at the Ohsumi
Strait between mainland Kagoshima and Ohsumi Shoto, while P. paucidens was distributed northward from the Watase line, drawn at the Tokara Strait between the Ohsumi Shoto and Tokara Retto. These two species are thought to extend their distribution southward by means of the land bridge. Therefore, the extension of the distribution of $N$. denticulata and $P$. paucidens may be affected by the formation of the Ohsumi and Tokara Straits.

In the present study three Macrobrachium prawns, $M$. equidens, $M$. latimanus and $M$. gracilirostre, were confirmed to inhabit the Ohsumi Shoto (Tanega-shima, Yaku-shima and Kuchinoerabu-jima) (Table 1). Previous reports clarified the distribution of these species southward from Okinawa jima (Kamita, 1963; Shokita, 1975, 1979; Sho- 


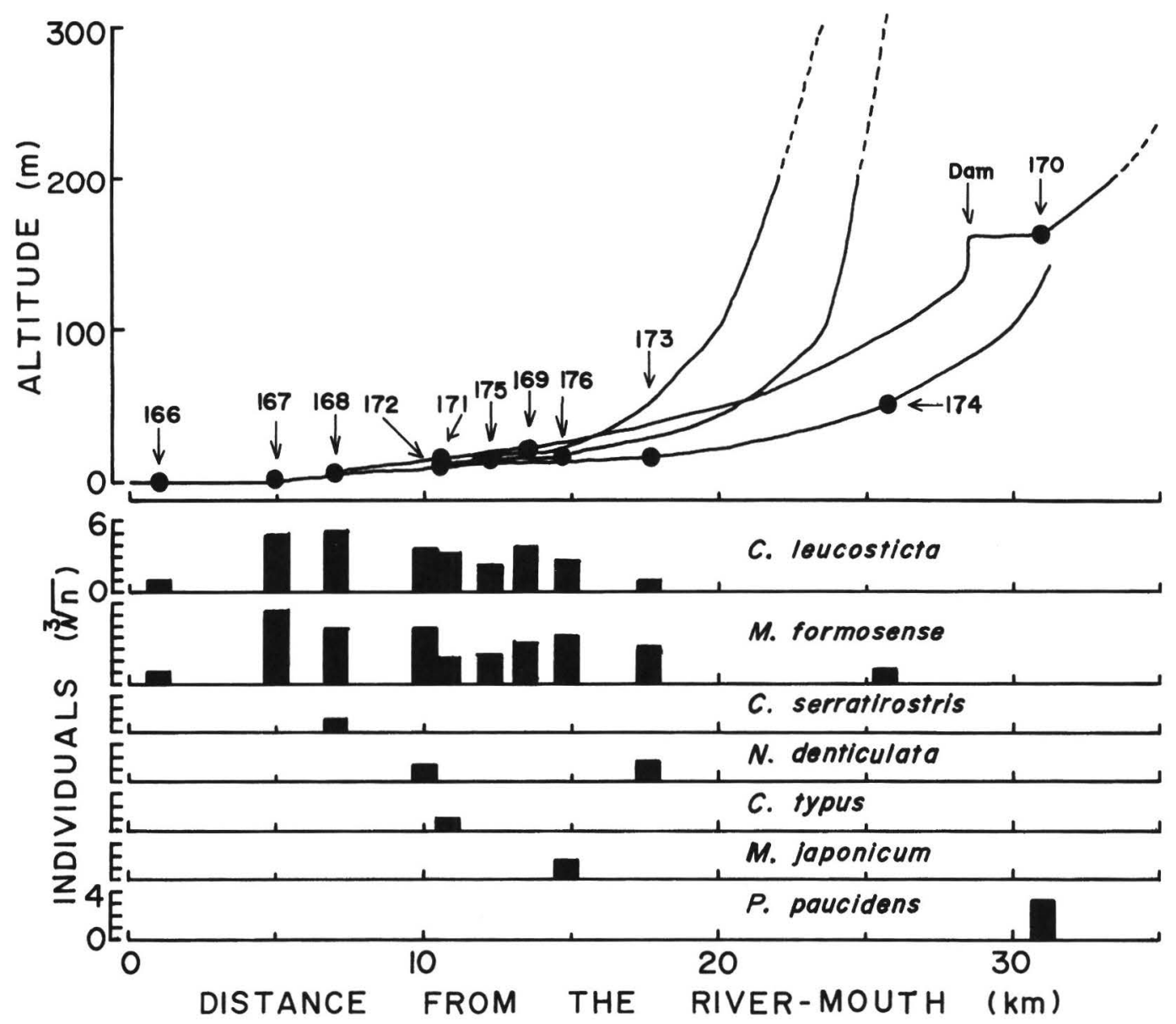

Fig. 4. Longitudinal distribution and abundance of inland water shrimps and prawns in the Kimotsuki River. Arabic numerals show the site number.

kita \& Nishijima, 1976, 1977). Female $M$. equidens produce some thousands of small eggs (average diameter $=0.79 \mathrm{~mm}$ ), and release pelagic larvae which develop in waters with 24.5-35.0 \% salinity (Ngoc, 1976; Shokita, 1979), however, the environmental factors affecting larval development of $M$. latimanus and $M$. gracilirostre are still unknown. Shokita (1979) reported that the females of these species produce two to three thousand small eggs (average diameter $=0$. $69 \mathrm{~mm}$ ). Therefore, the larvae of these shrimps are inferred to develop in sea water with similar qualities as those for $M$. equidens. The three Macrobrachium prawns could extend their distributions to the Ohsumi Shoto by larval dispersal through the Kuroshio Current.

Though seven southern species were found to be common to the Satsuma Peninsula of mainland Kagoshima and Yakushima, ten were found to be common to the Ohsumi Peninsula of mainland Kagoshima and Yaku-shima. These results suggest that Ohsumi Peninsula is influenced more strongly by the Kuroshio Current, and that the climatic conditions of this area are more tropical than those of the Satsuma Peninsula.

Although the distributions of C. japon- 


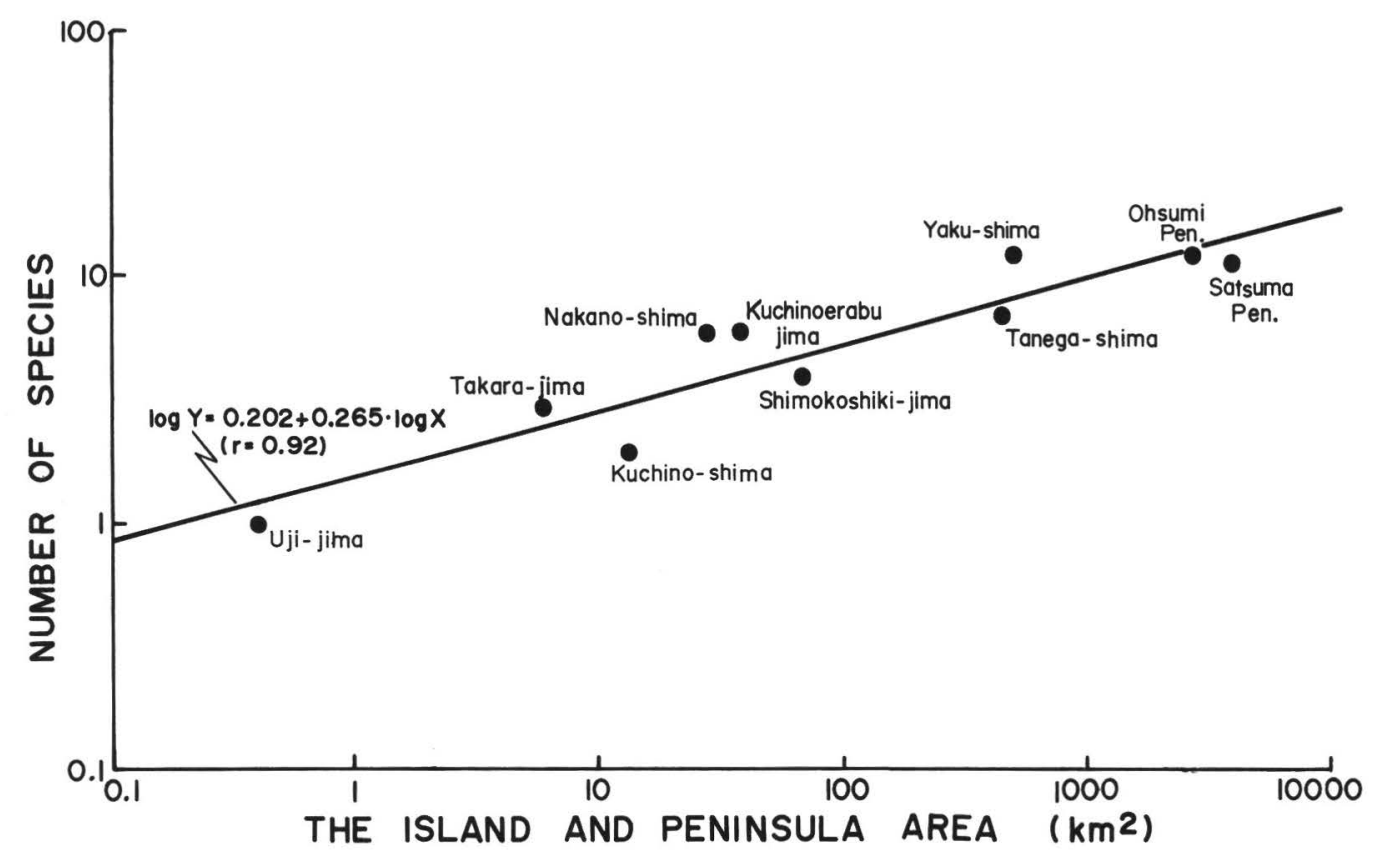

Fig. 5. Relationship between the number of species of shrimp and the area of surveyed islands and peninsula. Both axes are expressed as the common logarithmic scales.

ica, M. lar, and M. formosense overlapped in the east Asian region (Holthuis, 1950; Shokita, 1975, 1979), the two species, $C$. japonica and $M$. lar, are also distributed in the islands of Tokara Retto but M. formosense was not found in these islands (Table 1). Similar results were reported in previous studies (Shokita, 1975, 1979; Shokita \& Nishijima, 1977). Hamano \& Hayashi (1992) reported that the juveniles of $C$. japonica climbed a vertical wall in the Shiwagi Rivulet, Tokushima. Lee \& Fielder (1979) also observed the vertical climb of M. australiense on a $6 \mathrm{~m}$ high weir. The different distributions found among the three species, C. japonica, M. lar and $M$. formosense, may have resulted from the different ecological characteristics found in each species such as the process of larval recruitment, climbing ability of juveniles and survival of juveniles after settlement. These hypotheses require future study.

As mentioned above, the geographical distributions of freshwater shrimps and the faunal composition in the surveyed areas may be affected by island size, the Kuroshio Current, the form of the river, and the migratory ability of each species.

Longitudinal distribution: In the three surveyed rivers, the amphidromous species, C. leucosticta, M. formosense, C. serratirostris, C. typus, and M. japonicum, were found to inhabit slow flowing reaches near the river mouth (Figs. 2-4). On the contrary, only landlocked $N$. denticulata and $P$. paucidens were distributed upstream from the dam or in the steep reaches. The longitudinal distribution in these three rivers would be also affected by a dam or a natural vertical wall as reported by previous studies (Kamita, 1970; Shokita, 1979, 1982, 1990; Miya \& Hamano, 1988; Hamano \& Hayashi, 1992).

In the Sendai and Kimotsuki Rivers, $P$. paucidens, instead of $N$. denticulata, was distributed in the artificial lake or in the areas upstream from the dam (Figs. 2, 4). Palaemon paucidens was distributed further 
upstream in the surveyed rivers than $N$. denticulata. However, $N$. denticulata was found to inhabit more upstream locations when P.paucidens was absent (Fig. 3). Miya \& Hamano (1988) reported that after a dam has been built across the Yukinoura River, Nagasaki, N. denticulata expanded its distribution into the artificial lake on the river. In the Yukinoura River $P$. paucidens was absent. These two landlocked species, therefore, may compete with each other for habitat in the upper reaches of the river.

Lastly, the longitudinal distribution of shrimps in a river may be affected by the form of the river and the life history of each species.

\section{Acknowledgments}

We thank Dr. C. L. McLay of the University of Canterbury, Dr. S. Shokita of the University of the Ryukyus, Dr. R. B. Manning of the Smithsonian Institution, and Mr. E. A. T. Floreto of Kagoshima University, for critically reading the manuscript.

\section{Literature Cited}

Ekman, S., 1953. Zoogeography of the sea. xiii + $417 \mathrm{pp}$. Sidgwick and Jackson Limited, London.

Hamano, T. \& Hayashi, K.-I., 1992. Ecology of an atyid shrimp Caridina japonica (De Man, 1892) migrating to upstream habitats in the Shiwagi Rivulet, Tokushima Prefecture. Researches on Crustacea, 21: 1-13. (In Japanese)

Holthuis, L. B., 1950. The Decapoda of the Siboga Expedition. Part X. The Palaemonidae collected by the Siboga and Snellius expeditions, with remarks on other species. I. Subfamily Palaemoninae. Siboga Expeditie, 39a : 1-268

Kamita, T., 1963. Fresh-water shrimps and prawns of Amami-oshima, Yaku-shima and Tanegashima. Bulletin of the Shimane University (Natural Science), No. 13: 1-28. (In Japanese)

-1970 . Studies on the fresh-water shrimps, prawns and crawfishes of Japan. 213 pp.,
Sonoyama Shoten, Matsue. (In Japanese)

Kawai, H. ed., 1991. Nagare to seibututo - suisan kaiyohgaku tokuron -. 410 pp., Kyoto University Press, Kyoto. (In Japanese)

Kimoto, S., 1979. Minami no shima no ikimonotachi. 203 pp., Kyoritsu Shuppan, Tokyo. (In Japanese)

Lee, C. L. \& Fielder, D. R., 1979. A mass migration of the freshwater prawn, Macrobrachium australiense Holthuis, 1950 (Decapoda, Palaemonidae). Crustaceana, 37 (2): 219-222.

MacArthur, R. \& Wilson, E. O., 1967. The theory of island biogeography. 203 pp., Princeton University Press, Princeton, N. J.

Miya, Y.\& Hamano, T., 1988. The influence of a dam having no fishway on the distribution of decapod crustaceans in the Yukinoura River, Nagasaki, Japan. Nippon Suisan Gakkaishi, 54 (3): 429-435. (In Japanese)

Ngoc-Ho, N., 1976. The larval development of the prawn Macrobrachium equidens and Macrobrachium sp. (Decapoda: Palaemonidae), reared in the laboratory. Journal of Zoology, London, 178; 15-55.

Shokita, S., 1975. The distribution and speciation of the inland water shrimps and prawns from the Ryukyu Islands-I. Bulltein of Science and Engineering Division, University of the Ryukyus, No. 18: 115-136. (In Japanese)

, 1979. The distribution and speciation of the inland water shrimps and prawns from the Ryukyu islands-II. Bulltein of Science and Engineering Division, University of the Ryukyus, No. 28: 193-278. (In Japanese)

-1982 . Longitudinal distribution of caridean shrimps (Atyidae and Palaemonidae) in the rivers of the Ryukyu Islands. Aquabiology, No. 18: 57-63. (In Japanese)

,- 1990 . Inland-water macrofauna and their fluctuations in the northern part of Okinawa Island, the Ryukyus. Biological Magazine of Okinawa, 27: 3-13. (In Japanese)

\& Nishijima, S., 1976. Faunal list of inlandwater malacostraca of Amami group, the Ryukyu Islands. Ecological Studies of Nature Conservation of the Ryukyu Islands, 2: 31-38. - \& - 1977. Land and inland-water crustaceans of northeastern Ryukyus, the Ryukyu Islands. Ecological Studies of Nature Conservation of the Ryukyu Islands, 3: 185202.

Tokuda, M., 1969. Biogeography. 199 pp., Tsukiji Shokan, Tokyo. (In Japanese)

Marine Biological Laboratory, Faculty of Fisheries, Kagoshima University, Shimoarata 4-50-20, Kagoshima 890, Japan. 